\title{
Amor e resiliência: a docência no ensino superior em tempos de pandemia do Novo coronavírus (covid-19)
}

\section{Love and resilience: higher education teaching in times of the New Coronavirus pandemic (covid-19)}

\author{
${ }^{1}$ Adilson Anacleto adilson.anacleto@unespar.edu.br \\ ${ }^{2}$ Ana Paula Oliveira Becker Alvarenga \\ ${ }^{3}$ Aline Rafaely Sousa Ferreira
}

\section{RESUMO}

A pandemia ocasionada pelo coronavírus (COVID-19), transformou profundamente a vida social no Brasil, sendo que o ensino superior também sofreu alterações com a adoção do ensino remoto na maioria das instituições, no entanto sob a percepção do professor, ainda não foram realizados estudos que avaliem esse cenário modificado. Neste contexto, apresenta-se resultado de pesquisa exploratória descritiva realizada junto a trinta professores de universidades públicas no Paraná durante a pandemia, entre os meses de abril e maio de 2020 na qual visou compreender o cenário atual e as implicações da docência no ensino superior público durante a pandemia ocasionada pelo novo coronavírus (COVID-19). O estudo revelou que, entre os problemas mais recorrentes na docência durante o período investigado, foram a ampliação da carga de trabalho, atividades geradas com o ensino de forma remota, dificuldade de operacionalizar múltiplas plataformas de ensino e, ainda, manter a qualidade de ensino. A maioria dos docentes relataram problemas pessoais e psicológicos decorrentes da pandemia sendo que os mais citados são a ansiedade e a insônia. As principais ações de enfrentamento foram o ensino e aprendizagem entre colegas de profissão para o domínio de novas tecnologias educacionais, a resiliência e a empatia com discentes em período atípico. A pandemia impactou de forma profunda a vida dos docentes obrigando os mesmos a terem comportamento proativo, interagindo com colegas de trabalho tendo a intenção de aprender e aprendendo com a intenção de ensinar.

Palavras-chave: Resistência. Educação superior. Universidade pública.

\begin{abstract}
The pandemic caused by the New coronavirus (COVID-19), has profoundly transformed social life in Brazil, and higher education has also undergone changes, especially with the adoption of remote education in most institutions, however, under the teacher's perception, few studies carried out to evaluate this scenario. In this context, the results of a descriptive exploratory research carried out with 30 professors from public universities in Paraná during the pandemic between April and May 2020 are presented. The study aimed to understand the current scenario and the implications of teaching in higher education during the pandemic caused by the New coronavirus. The study revealed that the most recurring problems were the expansion of the workload and activities generated by teaching remotely, the difficulty of operating multiple teaching platforms and still maintaining the quality of teaching. Most teachers reported personal and psychological problems during this period, the most cited being anxiety and insomnia. The main coping actions were teaching and learning among professional colleagues to master new educational technologies, resilience and empathy with students in an atypical period. The pandemic had a profound impact on teachers' lives, forcing them to be proactive, where they interacted with co-workers with the intention of learning and learned with the intention of teaching.
\end{abstract}

Keywords: Resilience. College education. Public university.

\footnotetext{
1 Professor adjunto do Colegiado de Administração. Professor permanente do Programa de Mestrado em Ambientes Litorâneos e Insulares PPG-ALI - Campus de Paranaguá. Professor permanente do Programa de Mestrado Interdisciplinar em Sociedade e Desenvolvimento PPGSeD - Campus de Campo Mourão.Universidade estadual do Paraná - Unespar. http://orcid.org/0000-0003-1050-4643

2 Mestranda Programa de Pós-Graduação Interdisciplinar Sociedade e Desenvolvimento - PPGSeD. Universidade Estadual do Paraná.

3 Mestranda Programa de Pós-Graduação Interdisciplinar Sociedade e Desenvolvimento - PPGSeD.
} 


\section{INTRODUÇÃO}

O mundo conheceu em 2020 a maior pandemia do último século que tem ceifado vidas e já atingiu mais de 188 países tornando um problema epidemiológico que afetou milhões de pessoas. O novo vírus chamado de coronavírus, denominado como SARS-COV-2, causa a doença chamada de COVID-19, acrônimo em inglês de Coronavirus Disease 2019, e devido a sua alta taxa de contágio, trouxe consigo uma série de respostas impostas pelos governos a fim de conter a contaminação (SENHORAS, 2020).

O avanço do vírus a nível mundial obrigou que o governo, além das tradicionais medidas de saúde pública, como: higiene, distanciamento social, restrição do tráfego aéreo, transportes, determinasse também a quarentena, sendo o isolamento social a forma de diminuir a disseminação do vírus, até que se encontre um tratamento efetivo, o que ainda é inexistente até o momento, bem como pela prevenção de um colapso dos sistemas de saúde brasileiro (PALÁCIO; TAKENAMI, 2020).

$\mathrm{O}$ isolamento social alterou a vida das pessoas, o que repercutiu em uma série de impactos a realidade humana em suas diferentes dimensões e complexidades. A educação também foi afetada, tanto que uma das primeiras recomendações da OMS (2020), foi justamente a suspensão das aulas no formato presencial e o fechamento temporário das escolas em todos os níveis educacionais (OMS, 2020).

Assim, a pandemia impôs aos estudantes e professores do ensino presencial, em curto espaço de tempo, a necessidade de adaptação a um cenário até então por eles desconhecidos, quando tiveram que migrar os processos de ensino de aprendizagem presencial para o formato intitulado ensino remoto emergencial.

As tecnologias digitais de informação e comunicação (TDIC), segundo Palácio e Takenami (2020), que têm exercido papel fundamental, e são consideradas aliadas no processo educacional em tempos de pandemia, não somente na divulgação de informações pertinentes à doença, mas também, tem oferecido um grande contingente de aplicativos, ferramentas digitais e práticas inovadoras em educação que tem sido usada pelos professores nesse período. No entanto, apesar de disponível em quantidade, as tecnologias digitais não apresentam soluções facilitadas no novo contexto da vida educacional devido a que tradicionalmente os professores e professoras são mais consumidores da tecnologia do que produtores de conteúdo pedagógicos, no entanto, superar esse desafio tem sido configurado como espaço de luta na democratização do ensino, uma vez que significativa parte dos alunos e alunas não possuem acesso à internet e, tampouco, dispõem de espaço adequado ao estudo em seus lares (Barreto, Rocha, 2020).

No que tange ao ensino superior, as universidades em sua maioria, também foram levadas a se adaptar bruscamente ao ensino remoto (ARRUDA, 2020), o que segundo Barreto e Rocha (2020) se mostra nesse momento como alterativa única ao não cancelamento do ano letivo.

Especificamente sobre as universidades públicas do Estado do Paraná, a maioria também adotou o modelo de educação remota emergencial, não obstante essa forma de ensino tem imposto aos professores em contexto geral significativos impactos, segundo a OMS (2020) variam desde os aspectos econômicos como a redução da renda para professores horistas, e também, tem provocado profundos impactos psicológicos como estresse e ansiedade. Os impactos econômicos, sociais e psicológicos podem estar sendo ainda mais agravados diante da urgente necessidade de adaptação ao ensino remoto, o que implica em uma nova forma de ensinar, em regime de urgência, que em muitos casos, pode se tornar expositiva como indivíduo, dado que os professores nem sempre se sentem preparados ao desafio dessa nova etapa, no entanto, apesar da severa transformação, ainda são poucos os estudos que revelem o panorama das dificuldades vivenciadas pelos docentes em período de pandemia.

O que pensa o professor no ensino superior sobre esse cenário? Quais são suas limitações e suas potencialidades para o enfrentamento dessa pandemia? Que tipo de suporte social, psicológicos e profissional tem 
recebido? Essas são questões que ainda não possuem respostas até o presente momento, e considerando que é urgente conhecer quais são as percepções dos professores do ensino superior em relação ao ensino remoto em tempos de isolamento social, este estudo objetivou investigar o cenário atual e as implicações da docência no ensino superior público durante a pandemia ocasionada pelo novo coronavírus (COVID-19).

\section{METODOLOGIA}

A pesquisa exploratória descritiva foi aprovada pelo Comitê de Ética em Pesquisa sob o parecer $\mathrm{n}$. 39375120.0.0000.9247, e foi realizada junto a trinta professores de universidades públicas do Estado do Paraná entre abril e maio de 2020. A pesquisa quanto à natureza, de acordo com Vergara (2015), é qualitativa em função de que se visou a coleta de dados com base na auto percepção dos professores entrevistados sobre o cenário atual, sem se preocupar com o uso de técnicas estatísticas. A pesquisa ocorreu remotamente, após os respondentes concordarem em participar do estudo, respondendo questões nos aspectos da docência, bem como dos impactos psicológicos sentidos pelos entrevistados.

Após a coleta de dados similarmente ao proposto por Negrelle et al (2012), foi organizada uma matriz de impacto cruzado, onde os autores descrevem a matriz como sendo o cruzamento das implicações entre si, e posteriormente das oportunidades entre si, mediante o relato da auto percepção dos entrevistados. A matriz emprega valores percentuais de 0 a 100 a cada opinião exposta pelos entrevistados em relação as demais opiniões expressadas, comparando cada item analisado na relação de influência exercida e a influência sofrida nas práticas cotidianas da docência durante o ensino remoto, assim quanto maior o índice, maior é a relevância e a atenção a ser dada a situação e os problemas vivenciados pelos docentes.

A matriz de impacto gera um índice de relevância e importância na percepção docente para o melhor desempenho do trabalho e segundo Anacleto e Prazeres (2020) pode ser obtido pela equação:

\section{$I R=\underline{F A} \times \mathrm{FB} \times 100$}

\section{$\sum \mathrm{SF}$}

IR= Índice de Relevância da situação avaliada;

FA = Índices de influência recebida;

FB = Índices de influência provocada;

$\sum \mathrm{SF}=$ Somatória dos índices (FA x FB) de todas as questões analisadas.

Finalmente de acordo com o proposto por Vergara (2015), foi adotada a análise interpretativa, realizada por meio da técnica de triangulação de dados com agrupamentos similares, sendo o foco classificar elementos que pudessem ser percebidos como similares ou relativamente homogêneos com base no conjunto de questões pesquisadas, buscando homogeneizar os objetos possíveis dentro de grupos e simultaneamente maximizar a heterogeneidade entre o grupo investigado. 


\section{RESULTADOS}

O estudo revelou que entre os entrevistados 50\% eram doutores, $30 \%$ eram mestres e $20 \%$ especialistas, sendo que o tempo de dedicação à docência era em média de 8,3 anos, o que revelou que o grupo de entrevistados apresentavam significativa experiência na docência. A primeira, e mais importante, situação revelado pelo estudo é que a maioria dos entrevistados $(\mathrm{n}=85 \%)$ se sentiam abandonados pela esfera governamental no que tange ao desenvolvimento das atividades após o início da pandemia, e que não receberam de forma antecipada capacitação ou treinamentos para o ensino de forma remota. As orientações sobre operacionalização das plataformas adotadas chegaram em média 21 dias após o reinício das aulas durante a quarentena, ou seja, quando as orientações chegaram aos professores, os mesmos já estavam exercendo a atividade.

As implicações pessoais de enfrentamento a pandemia, ou seja, aquelas que não são de ensino porém eram relacionadas em questões de múltiplas respostas, destacaram-se o temor pela exposição de aulas gravadas e um modelo de ensino sem amplo domínio ( $\mathrm{n}=63,3 \%)$, receio de produzir conteúdo e disponibilizar na internet $(\mathrm{n}=46,6 \%)$ e a dificuldade de organização pessoal para as aulas remotas no ambiente familiar $(n=36,6 \%)$, ainda nesse contexto, ao primeiro mês de ensino remoto $63,3 \%$ dos entrevistados revelaram que já haviam sido tema de brincadeira digital por "memes" e outras formas de escarnio por parte dos alunos com a postura ou erros do professor nas aulas remotas, sendo que deste grupo $50 \%$ se sentiram constrangidos ou ofendidos com a brincadeira.

Os entrevistados em questões de múltiplas respostas relataram problemas que os mesmos consideraram psicológicos, e que eram oriundos do isolamento social e da ausência das atividades cotidianas, sendo os mais citados: a insegurança pelos familiares $(n=100 \%)$, temor do futuro $(n=96,6 \%)$, cansaço mental $(n=80 \%)$ ansiedade $(n=80 \%)$, insônia $(n=63,3 \%)$, temor constante $(n=63,3 \%)$, estresse $(n=50 \%)$, irritabilidade $(n=20 \%)$ e sentimento de prisão e claustrofobia com o isolamento $(\mathrm{n}=5 \%)$.

A pandemia também provocou alterações no que se refere as atividades laborais, segundo os entrevistados, a ampliação da carga de trabalho e as dificuldades de operacionalização de múltiplas plataformas de ensino sendo assim, os fatores que geraram as maiores implicações (Tabela 1).

Tabela 1 - Principais implicações relativas as atividades docentes no ensino emergencial remoto na auto percepção de professores no ensino superior $(n=30)$

\begin{tabular}{clc}
\hline & \multicolumn{1}{c}{ Implicações } & Índice de Relevância \\
\hline 1 & Ampliação da carga de atividades docente & 27,01 \\
\hline 2 & $\begin{array}{l}\text { Dificuldade de operacionalização de múltiplas } \\
\text { plataformas de ensino e de forma simultâneas }\end{array}$ & 20,03 \\
\hline 3 & Preocupação em manter a qualidade de ensino & 16,12 \\
\hline 4 & $\begin{array}{l}\text { Dificuldade de interação com os alunos nas atividades } \\
\text { remotas }\end{array}$ & 16,12 \\
\hline 5 & $\begin{array}{l}\text { Falta de preparo para o exercício de aulas remotas } \\
\text { emergenciais } \\
\text { Reeeiópela exposięão nas aulas gravadas pela falta de } \\
\text { experiência (memes) }\end{array}$ & 9.01 \\
\hline 7 & $\begin{array}{l}\text { Diminuição da motivação e frequência dos alunos } \\
\text { Falta de estruturas adequadas das universidades para o } \\
\text { exercício emergencial das aulas remotas } \\
\text { Influeneias dos problemas individuais dos alunos nos } \\
\text { rendimentos }\end{array}$ & $\begin{array}{l}\text { Dificuldade na realização de avaliações de atividades e } \\
\text { trabalho dos alunos }\end{array}$ \\
\hline 8 & & 5,22 \\
\hline 10 & & 4,21 \\
\hline
\end{tabular}

Fonte: $\mathrm{O}$ autor 
A necessidade de reação diante de um cenário inusitado e da necessidade de ações e novas competências para o enfrentamento da pandemia estabeleceu entre os docentes a criação de vínculos que antes da pandemia não eram tão fortemente praticados (Tabela 2).

Tabela 2 - Competências essenciais na auto percepção dos docentes no ensino superior desenvolvidas para o enfrentamento da pandemia da COVID-19 $(n=30)$

\begin{tabular}{clc}
\hline & Competências desenvolvidas pós pandemia do Novo coronavirus & Índice de Relevância \\
\hline 1 & Reavaliação da práxis pedagógica & 14,96 \\
\hline 2 & Ensino e aprendizagem entre colegas de trabalho & 13,29 \\
\hline 3 & Domínio de novas tecnologias educacionais & 12,36 \\
\hline 4 & Resiliência & 12,09 \\
\hline 5 & Maior empatia com discentes & 11.64 \\
\hline 6 & Inovação no ensino & 11,59 \\
\hline 7 & Criatividade nas aulas remotas & 10,04 \\
\hline 8 & Compartilhamento de informações entre docentes & 9,66 \\
\hline 9 & Uso de mídias digitais das novas gerações no ensino aprendizagem & 8,32 \\
\hline 10 & Interações sociais via web & 7,69 \\
\hline
\end{tabular}

Fonte: $\mathrm{O}$ autor

A totalidade dos entrevistados relataram fazer uso de, no mínimo, duas ferramentas digitais simultâneas para atender, de forma ampla, todos os discentes. Entre as mídias digitais mais utilizadas nos processos de ensino destacaram o WhatsApp, usado pela totalidade dos entrevistados, Moodle, E-mail, Google Classroom, Skipe, Zoom, Teams, Jitsi e o Facebook.

Quando questionados quais era os principais fatores que potencializaram as respostas ao enfrentamento da situação gerada pela pandemia, em questões de múltiplas respostas, sobressaíram o amor pela profissão $(\mathrm{n}=93,3 \%)$, a responsabilidade perante os alunos $(\mathrm{n}=86 \%)$, solidariedade entre colegas do local de trabalho $(\mathrm{n}=86 \%)$ e o compromisso com a comunidade e com a educação $(\mathrm{n}=80 \%)$.

\section{DISCUSSÃO}

O docente passa por várias etapas no magistério, segundo Huberman (2000), sendo a primeira relacionada ao "entusiasmo", onde a docência ainda que busque reconhecer a realidade dos discentes, apresenta muitas inseguranças em explorar, de forma satisfatória, as possibilidades da profissão. A segunda fase é classificada como a fase de "realidade" quando se descobre que não é possível promover todas as mudanças que se desejava. A terceira fase segundo Huberman (2000), é relativa a "estabilização", quando ancorado pela experiência e o crescimento educacional de pós-graduação, à docência apresenta autonomia em sua praxis pedagógica que influencia diretamente na formação dos discentes.

A pandemia do novo coronavírus (COVID -19) criou um cenário inusitado à medida que a experiência do docente não pode mais ser executada de forma integral como anteriormente, ocorrendo a obrigatoriedade de ensinar para além do tradicional, sendo que o quadro negro e o giz receberam outros diversos nomes, e os professores passaram de consumidor de conteúdo de ensino presencial para geradores de conteúdos para o mundo digital, nascendo assim justamente uma geração de estudantes nascida após a internet, e com maior domínio tecnológico e também mais críticos e mais jocosos, no que tange aos erros nas plataformas digitais e nas mídias sociais. 
Assim o ensino remoto gerou uma fase vivenciada similar a percebida no início da carreira, onde a inexperiência não permitia o exercício mais facilitado da profissão, situação agravada por não receber capacitação adequada, atuar em universidades sem estruturas de ensino remoto, desconhecendo em termos de produção de conteúdo a maioria das mídias sociais e suas interações com a educação, assim deve ser considerado que esse conjunto de situações pode ter ampliados os impactos psicológicos entre os docentes entrevistados, que além da pandemia em si, sofreram profundas mudanças nas práticas de docência. As mudanças em contexto geral provocam desconforto emocional diferente da dor física, e sim abalo psicológico, conforme relatados pelos docentes entrevistados.

A insegurança, o medo e temor nos impele a buscar a solução para os processos de mudanças instalados, e no que tange à docência, Alves (2006) descreve que as mais variadas formas de afeto e sentimentos podem ser considerados alavancas para promover a mudança e transformação de um cenário adverso gerando novas atitudes positivas e benéficas a discentes e docentes. $\mathrm{O}$ afeto na forma de amor à docência resulta, conforme citado nesse estudo, a mola propulsora para que ocorra a ressignificação e o auto compromisso na busca pela instalação de uma nova práxis, que sobreponha o que é novo e impositivo. Assim, o novo se faz passado e um novo "novo" se sobrepõe sobre o severo processo de mudança instalado, portanto, o amor pela profissão apesar dos desconfortos gerados tem sido observado como um dos principais motivadores nas condições de enfretamento a situação pandêmica instalada.

O maior índice de influência no presente estudo, no que tange as respostas ao enfrentamento da pandemia (Tabela 2), indica que os docentes tiveram atitude mais proativa na reavaliação da práxis pedagógica adotada, e que, os novos conceitos deveriam estar associados as respostas necessárias ao momento vivido, considerando também os múltiplos problemas enfrentado pelos discentes, desde o mais básico ao ensino remoto, como a falta de acesso a computadores e a internet para poder assistir as aulas. Quanto aos docentes, para além de questões como recompensas financeiras, em sua maioria pensam nas condições dos alunos e suas dificuldades impostas a aprendizagem e, expressam seus sentimentos de solidariedade e amor à docência na forma de compromisso e responsabilidade com a educação. Esse conjunto de fatores provavelmente foi o fator decisivo para que a retomada das aulas no ensino superior ocorresse ainda que não ancorada em ações de estado ou das cúpulas universitárias.

Seria ingênuo afirmar que, esses procedimentos ocorreram com a totalidade dos docentes no ensino superior, mas ainda assim, é possível afirmar que em tempos atípicos, o amor pela profissão é a redescoberta daquilo que podemos oferecer de alento, criando vínculos e praticando a empatia com os discentes resultando em um processo onde apresentam o comportamento similar a transição de início de carreira conforme descrito por Huberman (2000) como sendo a fase do entusiasmo, onde os docentes buscam apoio em seus pares para a melhor execução da docência. Assim, no estudo revelou um comportamento onde o docente "interage com seus parceiros de trabalho com a intenção de aprender, e aprende com seus parceiros de trabalho com a intenção de ensinar", então não há dúvidas em responder a questão norteadora desta pesquisa, qual seja, o amor à profissão promove significativa mudança por parte dos docentes, criando em si e de forma coletiva, ações e condições de enfretamento a pandemia do novo coronavírus (COVID-19), dado que esperar que as respostas viessem do poder público. Provavelmente os discentes estariam fadados a perder o ano, e apesar de todas as dificuldades observadas no ensino emergencial remoto, os docentes tem ajudado os alunos a superarem um dos tempos mais difícil das últimas décadas.

Urge considerar que, a pandemia expôs de forma mais acentuada a realidade vivida pelos professores universitários em seu no dia a dia, e também, no que tange a pouca ou ausência de equipamentos, laboratórios desatualizados e insuficientes, falta de técnicos administrativos de apoio e em especial a ineficácia da política pública educacional que não atende as demandas mínimas de igualdade educacional dos discentes, que são excluídos do mundo digital, e assim suprime um direito constitucional de acesso à educação.

A preocupação dos docentes com a situação pandêmica coincide com o descrito por Martuccelli (2016) que, para as pessoas que possuem renda que permitam boa sobrevivência, a felicidade acaba por ancorar nas 
aspirações pessoais, se deslocando para valores espirituais ou pós-materialistas como a família, a saúde e trabalho e um crescente consenso em torno da legitimidade fundamental do amor como algo que de sentido da vida. Assim neste contexto, a rápida resposta advinda ao enfrentamento a pandemia por parte dos docentes pode ter origem no amor a profissão e na resiliência. Situações de pressão ocasionada pelo cenário pode resultar em rápidas capacidades de respostas de indivíduos e comunidades inteiras na busca pela mitigação dos problemas e das pressões desgastantes.

Assim surge a necessidade da resiliência e afloram forças ligadas a sentimentos que impulsionam e facilitam as ações profissionais para a superação de dificuldades, conforme também descrito por Vergara (2008), onde sugere que sentimentos derivados da subjetividade humana como amor e ódio, racionalidade e irracionalidade, solidariedade e a esperança podem desencadear o uso de recursos dantes intangíveis na busca pelo bem comum. Segundo Martuccelli (2016), o amor está relacionado ao exercício como cidadão que imputa a doação de si mesmo em prol de uma causa coletiva, e conforme relatado por Fossatti et al. (2016), o êxito docente esta relacionados a valores atitudinais tais como compromisso, amor pela profissão, diálogo, dedicação, e companheirismo, que também, são características das pessoas resilientes.

O estudo revelou que, mesmo diante da inoperância do Estado, mesmo diante das lentas respostas dos gestores universitários, e um cenário perverso a professores e alunos, professores que de fato possuem os mais nobres sentimentos pela docência e respeito por seus alunos resistem, usam seus próprios equipamentos, compram seus próprios equipamentos, praticam o autodidatismo, transformam quartos, salas e até varandas em sala de aula, mas não desistem e nem abandonam seus alunos.

A rotina diária, além do cuidar de filhos, maridos, esposas, afazeres domésticos e laborais, incluiu também baixar programas, preparar de forma mais minuciosa as aulas, preparar e gravar vídeos, áudios, criar canais em redes sociais, fazer a gestão de múltiplas plataformas e ferramentas de ensino pensando nos alunos que não possuem acesso facilitado as tecnologias, esses professores se expõe, arriscam, "dão a cara", doam de si sem pensar em si, para se obter o resultado que almeja.

Ainda que se sentindo abandonados, à docência resiste, enfrenta com vigor a pandemia que se mostra implacável, devastando vidas e famílias inteiras, e entre a dor do momento presente e as necessidades do momento atual, urge que a vida seja a prioridade. A educação superior pública no Brasil resiste mesmo diante de sucessivos ataques, redução orçamentária, falta de reposição das vagas de professores e agentes técnicos de suporte a educação. Essa situação cria um cenário de muitas dificuldades ao exercício da docência, mas ainda assim, em sua grande maioria, os professores seguem dedicados em sua missão de promover o diálogo entre os saberes e o conhecimento.

\section{CONSIDERAÇÕES FINAIS}

Os docentes em sua totalidade relataram problemas em desenvolver as atividades laborais durante a pandemia e, entre os problemas mais recorrentes, foram citados a ampliação da carga de atividades gerada com o ensino de forma remota, a dificuldade de interação com os alunos de forma remotas, operacionalizar de múltiplas plataformas de ensino e de forma simultânea e ainda manter a qualidade de ensino.

A maioria dos docentes relataram problemas psicológicos decorrentes da ausência de contato social, tendo sido os mais recorrentes a insegurança, ansiedade, insônia, o temor constante e o estresse.

As principais ações de enfrentamento dos docentes para a adaptação ao ensino remoto durante a pandemia foram a reavaliação e redescoberta da práxis pedagógica, o ensino e aprendizagem entre colegas de trabalho, o domínio de novas tecnologias educacionais, a resiliência que permitiu ultrapassar barreiras e a empatia com discentes em período atípico. 
Apesar do cenário adverso, os professores que se sentem exauridos, continuam se esforçando no enfrentamento da pandemia, lutam para recuperar os alunos, atuam em múltiplas plataformas digitais, mesmo diante a forte elevação da carga de trabalho. O investimento de matérias e equipamentos com recursos próprios, aprender a reaprender, e finalmente os docentes em total desprendimento "interagem com seus parceiros de trabalho com a intenção de aprender e aprende com seus parceiros de trabalho com a intenção de ensinar", concluindo assim que, como a única explicação, é o amor profundo a profissão e os respeito pela educação e pelos alunos.

\section{REFERÊNCIAS}

ALVES, N. N. L. Amor à profissão, dedicação e o resto se aprende. Anais... In: Reunião anual da ANPED, Caxambu, 2006.

ANACLETO, A.; PRAZERES, A.S.G. Novo Coronavírus (COVID-19) e a crise econômica: impactos nas pequenas empresas. Revista Tecnologia e Sociedade, edição especial COVID 19, 2020.

ARRUDA, E. P. Educação remota emergencial: elementos para políticas públicas na educação brasileira em tempos de Covid-19. EmRede-Revista de Educação a Distância, v. 7, n. 1, p. 257-275, 2020.

BARRETO, A. C. F.; ROCHA, D. S. COVID 19 e educação: resistências, desafios e (im) possibilidades. Revista Encantar-Educação, Cultura e Sociedade, v. 2, p. 01-11, 2020.

FOSSATTI, P.; GUTHS, H.; SARMENTO, D. F. Perspectivas para o Bem-estar na Docência: Trajetória de Vida e Produção de Sentido. Revista Subjetividades, v. 13, n. 2, p. 271-298, 2016.

HUBERMAN, M. O ciclo de vida profissional dos professores. 2a ed. Porto: Porto Ed. 2000, 61p.

MARTUCCELLI, Danilo. (2016). O indivíduo, o amor e o sentido da vida nas sociedades contemporâneas. Estudos Avançados, 30(86), 147-165.

NEGRELLE, R. R. B.; ANACLETO, A. Extrativismo de bromélias no Estado do Paraná. Ciência Rural, v. 42, n. 6, p. 981-986, 2012.

OMS. Coronavirus Disease (COVID-19) Pandemic. Disponível em: < https://www.who.int/emergencies/ diseases/novel-coronavirus-2019>. Acesso em 24/05/ 2020.

SENHORAS, E. M. Coronavírus e Educação: Análise dos Impactos Assimétricos. Boletim de Conjuntura, v. 2, n. 5, p. 128-136, 2020.

PALÁCIO, M. A. V.; TAKENAMI, I. Em tempos de pandemia pela COVID-19: o desafio para a educação em saúde. Vigilância Sanitária em Debate: Sociedade, Ciência \& Tecnologia, v. 8, n. 2, p. 10-15, 2020.

VERGARA, S. C. A resiliência de profissionais angolanos. Revista de Administração Pública, v. 42, n. 4, p. 701-718, 2008

VERGARA, S. C. Metodologia de pesquisa. Rio de Janeiro: Atlas, 2015. 